\title{
A economia antiga e a arqueologia rural - algumas reflexões
}

\author{
NORBERTO LUIZ GUARINELLO \\ Departamento de História \\ Faculdade de Filosofia, Letras e Ciências Humanas \\ Universidade de São Paulo
}

\begin{abstract}
RESUMO: A documentação arqueológica sobre as casas de fazenda da Itália romana é muito abundante. No entanto, sua interpretação, como documentos, depende diretamente dos modelos sobre o funcionamento da economia romana. Este artigo analisa e contrapõe dois desses modelos, procurando refletir sobre a relação entre realidade empírica e interpretação.
\end{abstract}

PALAVRAS-CHAVE: História Romana, Arqueologia Clássica, Economia Antiga, Arqueologia da Paisagem.

\section{Introdução}

O modo como a tradição cultural européia, da qual somos herdeiros, apropriou-se e fez as contas com seu passado clássico é marcado por ambigüidades, divergências, contradições. Incontáveis movimentos artísticos e intelectuais retiraram sua inspiração e legitimidade da "herança" greco-romana ou, pelo contrário, definiram sua originalidade precisamente ao se contraporem às formas e aos valores "clássicos". Mesmo no campo específico dos historiadores, onde os juízos estéticos ou de valor são, talvez, menos importantes, as avaliações sobre o sentido e a posição do Mediterrâneo clássico em nossa própria história são conflitantes ou mutuamente excludentes. Tais conflitos de visão, embora presentes igualmente na historiografia política e social, são particularmente intensos entre os que estudam a natureza dos processos econômicos do mundo antigo.

Após décadas de intensa discussão, os historiadores da economia antiga debatem-se, ainda, em torno de questões fundamentais como a importância e difusão das relações mercantis no mundo greco-romano, a predominância de formas autárquicas de produção, o significado do desenvolvimento das técnicas produtivas, a determinação ou não dos vínculos econômicos pelas relações políticas, etc. É verdade que os últimos anos observaram um amadurecimento da discussão e um maior refinamento das posições em conflito. De certa forma, isto tornou inviáveis as posturas excessivamente radicais, que se fixavam no pressuposto de uma absoluta alteridade, ou de uma total semelhança dos antigos com nosso próprio tempo. Não é mais possível, hoje, discorrer sobre capitalismo, burguesia, operariado, indústria no mundo anti- 

algumas reflexões.

go com a desenvoltura de um E. Meyer ou de um M. Rostovtzeff. O mesmo vale para os herdeiros do "primitivismo", que não se aventuram a negar que os quatro séculos que viram a construção e consolidação do Império de Roma representaram, ao menos para certas regiões, um momento único na história econômica do Mediterrâneo antigo, pelo crescimento das trocas mercantis, pelo desenvolvimento da produção agrícola e artesanal, pelo emprego de novas técnicas e de novas formas de organização do trabalho. Por tais características, que the conferem um aspecto ao mesmo tempo arcaico e moderno, estes 400 anos são um dos pontos estratégicos do debate atual, e é sobre eles que centraremos agora nossa atenção.

\section{A Economia da Itália Romana - Modelos}

Os termos da discussão sobre o desenvolvimento da economia na Itália republicana e imperial podem ser melhor apreendidos através do exemplo de dois esquemas interpretativos contemporâneos, ambos de grande influência nos anos 80 e bastante difundidos. Comecemos

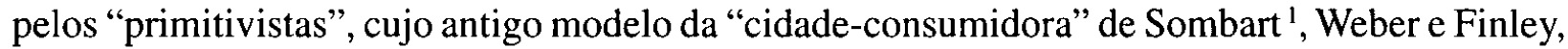
foi recentemente reproposto por P. Garnsey e R. Saller, no âmbito de um amplo estudo sobre a sociedade do Império romano (1987, p. 43 e ss.). Em suas formulações originais, vale lembrar, os "primitivistas" negavam a existência ou, ao menos, a importância, da produção mercantil no mundo greco-romano. A atividade artesanal era considerada meramente complementar e irrelevante em termos econômicos e a produção agrícola, esmagadoramente predominante, era localizada em unidades autônomas, auto-suficientes e autárquicas, no sentido aristotélico do termo. Garnsey e Saller, contudo, reconhecem a dimensão adquirida pelas trocas mercantis no Império romano e admitem, sem dificuldade, a importância fundamental dos mercados urbanos na estruturação da produção e na circulação de bens durante o Principado. Roma, sobretudo, é para ambos o grande mercado do período, consumindo vorazmente a produção agrícola da Itália e de diversas províncias. Tal mercado surge e se sustenta, contudo, através de mecanismos políticos - dados pela concentração do poder imperial na Urbe - e não por processos propriamente econômicos. $\mathrm{O}$ predomínio do "político" sobre o econômico" é um traço comum aos chamados "primitivistas" e encontra aqui uma formulação bastante coerente. Garnsey e Saller não se impressionam com a existência de grandes centros mercantis, assim como ignoram sua eventual retração e crise, precisamente onde e quando os "modernistas" (ou "neo-modernistas") apontarão, como veremos, uma inflexão da produção mercantil da Península.

Essa aproximação em direção às posições "modernistas", na verdade, tenta dar conta do estado atual das pesquisas sobre a produção econômica no Império, absorvendo novos elementos de informação, postos a nossa disposição pela pesquisa arqueológica. Mas isso não representa uma rendição. Pelo contrário, Garnsey e Saller colocam toda sua ênfase, precisamente, nos limites que a sociedade romana impunha ao desenvolvimento da produção mercantil: a despeito de qualquer crescimento na produção e na circulação de bens, a economia do Principado teria permanecido típica de uma sociedade subdesenvolvida ("underdeveloped"), caracterizada pelo domínio quase absoluto do setor agrícola, por um investimento produtivo reduzido (com o desvio da riqueza para o consumo conspícuo) e pela ausência de uma verdadeira "classe empresarial". Este último ponto merece ser visto com algum detalhe, pois é um dos "cavalos de batalha" desta tradição interpretativa.

O argumento básico sobre a ausência de uma classe empresarial centra-se em dois elementos: o destino final do lucro mercantil e a dependência ideológica e social dos negociantes frente aos proprietários de terras. A predominância de um sistema de valores oriundo da aristocracia fundiária e a manifesta hostilidade desta ao comércio ${ }^{2}$, teriam induzido os 
negociantes, segundo este raciocínio, a reinvestirem os lucros do comércio em terras, por serem - estas a fonte primeira de prestígio social e de poder político, com o consequiente abandono de suas atividades mercantis. A esta autofagia da classe mercantil se somariam, como fatores limitantes, as deficiências de certos elementos de infra-estrutura, como o pequeno desenvolvimento de uma legislação comercial apropriada ${ }^{3}$ e a ausência de inovações tecnológicas de porte na agricultura, estagnada a despeito de uma maior intensidade e especialização da produção ${ }^{4}$. Para Garnsey e Saller, deste modo,

"o poder essencial e a verdade do modelo da cidade-consumidora podem ser admitidos... a cidade era a base dos grandes proprietários de terras, que eram também seus habitantes mais ricos, e o centro e foco de suas despesas, que eram mantidas, em grande parte, por seus investimentos no campo" (1987, p. 49)

No âmbito de um tal modelo, a idéia de crise - como o ponto final de um desenvolvimento que, afinal, teria sido bastante limitado, tem escassa relevância (1987, p. 59 e segs.). Se mudarmos de ambiente cultural, no entanto, e nos deslocarmos do mundo anglo-saxão para a Itália, nos defrontaremos com um sólido e influente grupo de pesquisadores para os quais a noção de crise, como corolário de um conceito mais amplo de "modo de produção escravista", é uma peça chave em seu modelo interpretativo 5 . A ênfase, aqui, é toda outra: o desenvolvimento da economia itálica entre o final da República e o Principado é visto através das transformações nas forças e estruturas produtivas, sobretudo no campo $^{6}$, e a avaliação dos resultados desse processo é francamente positiva.

Segundo este modelo, a agricultura romana no período teria sido marcada pela sucessão de três formas principais de produção: a da tradicional pequena propriedade camponesa, em crise desde a guerra anibálica e já marginalizada no curso do século II a.C.; a da média propriedade escravista, centrada em uillae rusticae, que se expandiria notavelmente após a segunda guerra púnica, às expensas dos pequenos proprietários, florescendo até o século I d.C.; por fim, com a crise do escravismo, o desenvolvimento progressivo do latifúndio, visível desde o final da República e destinado a prevalecer sob o Principado. Destas, a forma intermediária, como resultado da inversão em terras públicas, ou nas antigas áreas camponesas, das riquezas acumuladas pela classe dirigente romana durante a expansão imperial, seria aquela mais dinâmica, a verdadeira responsável pelo grande desenvolvimento das forças produtivas e das trocas mercantis.

A "uilla escravista", reconhecível nas "descrições" dos escritores agrários, teria sido, assim, o verdadeiro motor da economia romana entre os séculos II a.C. e II d.C., introduzindo novas formas de cooperação e especialização do trabalho escravo e voltando-se decididamente para a produção mercantil destinada, sobretudo, aos mercados do Ocidente romano ${ }^{7}$. Essa combinação de escravidão com uma produção intensiva e com fins lucrativos comporia o que Carandini denominou de "um caso de desenvolvimento pré-capitalista", do qual seriam exemplos, igualmente, a "Idade Média tardia" e as monarquias absolutistas (1980, p. 14 e ss.).

Longe de se constituir num simples retorno às antigas concepções modernizantes, o modelo proposto por esta corrente atesta o grau de refinamento do debate contemporâneo: Garnsey e Saller parecem admitir, para a economia romana, uma fase de desenvolvimento moderado, sobretudo das trocas mercantis, mas preferem centrar-se no caráter limitado desse processo Já para Carandini, os fatores progressistas da economia romana são o centro mesmo das atenções, mesmo que esse "progresso" manifeste-se sob uma forma limitada. Centremo-nos, por um instante, nos limites desse desenvolvimento para os marxistas italianos.

Em primeiro lugar, o desenvolvimento impulsionado pelas "manufaturas escravistas" (Carandini,1979, p. 31) teria se limitado geograficamente à Itália central tirrênica ${ }^{8}$, formando o que Carandini definiu como uma "exceção dominante" (1980, XXV). Na formulação de G. Pucci, essa combinação conceitual de dominância e excepcionalidade visa conferir "a um sistema 
quantitativamente (geograficamente) minoritário uma hegemonia qualitativa, capaz de subordinar (comercialmente) regiões distantes e mesmo todo o Império, ao menos nos três ou quatro séculos em torno da era vulgar" (Pucci,1985,I,1,17). Há, portanto, uma limitação espacial ao desenvolvimento das forças produtivas e o "modo de produção escravista", embora se sobreponha e influencie formas mais arcaicas de produção, tem uma capacidade relativamente restrita de expansão e de penetração.

Já o balizamento cronológico é dominado pela idéia de crise: corroída por contradições internas e externas, a energia com que o "modo de produção escravista" gerou seu "desenvolvimento" se teria esgotado num breve lapso de tempo. As causas são as mesmas apontadas por Rostovtzeff (concorrência provincial) e por Staerman (dificuldades de gestão, ineslaticidade das unidades produtivas). A comprovação documental, no entanto, enfatiza as recentes descobertas da arqueologia: os mapas de distribuição de sítios rurais, que parecem colocar a crise no período antonino (Carandini,1985,I,1, 53) e, sobretudo, as ânforas, itálicas ou importadas, encontradas em camadas superpostas nas Termas do Nadador, em Óstia, o principal porto de Roma. Os gráficos elaborados a partir destas ânforas, por sua vez, parecem indicar um aumento geral das importações provinciais já em época Júlio-Cláudia, com o correspondente declínio das produções itálicas ${ }^{9}$.

Limites espaciais e cronológicos, portanto. Mas o traço mais original e fecundo da escola italiana talvez tenha sido a identificação de limites estruturais à produção de mercadorias no mundo romano: limites que seriam internos, intrínsecos às próprias unidades produtivas, ao modo como eram geridas as propriedades rurais. Seguindo um modelo desenvolvido por Witold Kula para a Polônia medieval, Carandini viu, na "uilla escravista" uma estrutura "bissetorial": no interior das uillae existiriam duas esferas distintas de produção, uma voltada para o mercado, com fins lucrativos e organizada racionalmente; a outra encarregada da subsistência da própria fazenda e de seus escravos, reproduzindo as antigas práticas da exploração camponesa (1983, p. 177 e ss. $)^{10}$. As esferas do mercado e da autarquia, desta forma, se combinariam de modo original, como as duas metades inseparáveis do próprio processo de produção escravista. O que as uillae possuíssem de dinâmico em seu setor mercantilizado, teriam também de arcaico na busca de uma auto-suficiência que as isolava, enquanto consumidoras, do próprio mercado ao qual destinavam parte de sua produção ${ }^{11}$.

Mesmo se levarmos em conta as influências e concessões mútuas, os dois modelos que empregamos nesta exemplificação parecem se contrapor frontalmente, como a estagnação se opõe ao crescimento. Dependem, na verdade, de visões completamente distintas da História humana e o debate entre os pesquisadores, a despeito de seu tom técnico e profissional, não deixa de expressar o confronto entre ideologias políticas diversas. Não é preciso insistir sobre este aspecto. Mais inesperado, talvez, é o fato de podermos identificar, entre os dois modelos, certas semelhanças não visíveis na superfície de suas discordâncias. Se os encararmos a uma certa distância, buscando suas perspectivas mais globais, veremos que certas semelhanças, pouco a pouco, tenderão a se sobrepor ao que pareciam ser diferenças fundamentais. Exploremos um pouco essa similitude.

Ambos os modelos, com efeito, atuam no âmbito de uma visão excessivamente uniforme e restrita da sociedade romana, em particular da sociedade rural, sempre descrita por meio de algumas categorias básicas - senadores, aristocracias municipais, camponeses. Garnsey e Saller concebem a estrutura agrária romana através de uma divisão mais ou menos rígida. Por um lado o que denominam "ricos" (wealthy), caracterizados por possuirem propriedades rurais complexas, fragmentadas, por vezes espalhadas em diferentes territórios. Os "ricos" podem ser subdivididos em três grandes categorias: a) nobreza local (local gentry), cujas terras se concentravam numa única região; b) senadores médios (middle ranking) e cavaleiros de origem municipal, que detinham propriedades em mais de um centro e c) os membros mais ricos da elite romana, com vastas 
propriedades na Itália e nas províncias. No outro extremo, e opondo-se aos ricos como um todo, os "camponeses pobres" (peasants), sobre os quais os textos antigos revelam pouco interesse e que sobreviviam praticando uma agricultura de subsistência, em pequenos lotes de terra, fosse como proprietários, em permanente declínio, ou como arrendatários ${ }^{12}$.

Essa simplificação da estrutura social do campo manifesta-se, de modo ainda mais acentuado, no grupo italiano, para o qual as "uillae escravistas" aparecem, com frequência, como o apanágio quase exclusivo das "elites dirigentes" de Roma (Pucci,1985,I,1,17), em particular de um reduzido círculo de famílias senatoriais (Carandini,1980,XXV). A esta elite fariam contraponto os pobres camponeses, reduzidos a uma agricultura de subsistência e em constante diminuição, frente à introdução maciça de estrangeiros escravizados. E a mão-de-obra escrava predominaria, já a partir do século II a.C., em diferentes áreas do mundo rural da Itália tirrênica. É importante insistir sobre a homogeinização que tais modelos impõem à interpretação do material arqueológico disponível, sobretudo das casas de fazenda, como veremos ${ }^{13}$.

Há, no entanto, uma semelhança menos evidente, uma confluência de perspectiva entre os dois modelos, que se deixa entrever no uso comum de categorias que soam estranhamente contemporâneas: "caso de desenvolvimento", "subdesenvolvido", "país em desenvolvimento"'14. Tais expressões, a despeito de seu significado aparentemente contrastante, expressam no fundo uma mesma perspectiva, um mesmo modo de olhar para o passado a partir do presente. Garnsey, Saller e Carandini partem, explicitamente, de uma certa imagem do mundo industrial contemporâneo em sua singularidade histórica, que atua, em seus textos, como o parâmetro oculto que anima a descrição e avaliação da economia romana ${ }^{15}$. É verdade, por outro lado que o modo de utilização desse parâmetro não é o mesmo. Garnsey e Saller trabalham com quantidades temporais discretas, com mundos distintos do nosso; voltam-se para o "outro". Para ambos, a descontinuidade entre Roma e o mundo contemporâneo não é uma mera questão de cronologia. Ela é uma relação lógica: a economia industrial capitalista age como uma espécie de medidapadrão de conceitos como desenvolvimento tecnológico, mercantilização e racionalidade, à qual são contrapostas as realizações econômicas do mundo romano. Estas últimas aparecem, assim, em negativo, definidas pelo que não são, por aquilo que não conseguiram atingir como meta ideal. O movimento interpretativo proposto por Garnsey e Saller assemelha-se ao do antropólogo que, saindo do mundo urbano atual, investiga realidades "primitivas" contemporâneas, cujo "atraso" é função de uma descontinuidade espacial, mental ou social, mas não do mero transcorrer de um tempo contínuo.

Já para o grupo italiano a sucessão cronológica tem uma importância fundamental. O presente é o ponto atual de um processo que abarca o conjunto da História humana e a ordena numa grande linha. Mas o tempo, tão fundamental, é visto sob um ângulo particular, que pode ser sintetizado pela famosa expressão de Marx: "a anatomia do homem é a chave da anatomia do macaco"16. Segundo a formulação de Massimo Brutti:

“...o presente (é) o nível a partir do qual se move a consciência, como totalidade na qual se distribuem, seguindo uma ordem diferente da de sua gênese, as categorias que reencontramos esboçadas ou justapostas em momentos prècedentes do processo histórico... O itinerário conceitual assim descrito tem como ponto de partida as formas fenomênicas mais acabadas, ou antes sua aparência, e tem como resultado a construção do esquema heurístico (crítico) que implica em pesquisa histórica sobre o passado e sobre a especificidade do presente" (Brutti, 1978:16-17) ${ }^{17}$.

Desta forma, enquanto Garnsey e Saller investigam o passado procurando demonstrar sua irredutibilidade absoluta ao presente, os marxistas italianos buscam antecipações, elementos do futuro - como mercado ou crescimento econômico - que se encontrariam, embrionariamente, no passado, e que se manifestariam segundo determinações próprias, porquanto não plenamente 
desenvolvidas. O conceito de "modo de produção escravista" que empregam não é senão a seleção e combinação dos elementos mais "modernos" da economia romana, cujo sentido histórico advém de sua posição particular enquanto momento na construção do presente (em termos lógicos $e$ cronológicos).

"Momento" é um termo frouxo: "etapa" expressaria possivelmente melhor essa noção de temporalidade, não fossem as conotações estalinistas da palavra. "Momentos”, em todo caso, não devem aqui ser entendidos como unidades temporais vagas e homogêneas de um tempo uniforme. Para este modelo, cada momento se propõe na História como uma entidade sui-generis, diferente de seus antecessores e sucessores, definida por um "modo de produção" que é dominante, mesmo que seja exceção. Daí a centralidade da noção de crise, que permite passar, aos saltos, de um "momento" determinado, de um "modo de produção", àquele que o sucede e supera. O conceito de "crise", para os marxistas italianos, passa assim a ocupar o lugar que fora da "Revolução", décadas atrás - um conceito que se podia aplicar a 1680, 1789, 1917, mas não, certamente, ao declínio do mundo greco-romano. De qualquer forma, tampouco esse conceito de crise parece dar conta da antigüidade tardia, que é, na verdade, uma ponte sem nome que liga, na história européia, o presente ao remoto passado ${ }^{18}$.

\section{Para além dos Modelos}

Um dos elementos-chaves dos modelos correntes para se interpretar a economia romana parece consistir, precisamente, nessa perspectiva teleológica de se encarar o passado. Procedimento que opera, a nosso ver, como que um achatamento, uma redução na historicidade plena dos fenômenos investigados. Definido um modelo de funcionamento da sociedade romana através de suas semelhanças e diferenças com o presente - este passa a atuar como uma entidade homogênea, sem ou quase sem história interna, válido como um todo para o período em que foram vigentes as condições utilizadas em sua definição. Garnsey e Saller, sobretudo, empregam uma delimitação temporal muito ampla, atuando no interior de um tempo longo, imóvel e amorfo, sem grandes transformações em seu decorrer. Mesmo para o grupo italiano, no entanto, o tempo é apreendido nos limites de uma determinada lei de transformação, uniforme e cadenciada, que identifica uma certa sucessão de fases de crescimento, entre os séculos II a.C. e II d.C., e depois uma crise abrupta.

Tais modelos, de filiação marxista ou weberiana, são úteis, sem dúvida, para se enquadrar e explicar processos históricos de longa duração. Mesmo sua perspectiva "presentista", que parte da suposta ordenação do real no presente para analisar sociedades passadas, tem seus pontos de interesse e é, em certa medida, inevitável. Modelos, contudo, pela ordenação lógica e estruturada que conferem à realidade, correm o risco de se converter em "camisas de força" do pensamento, atalhos que obviam a complexidade e as contradições inerentes às próprias fontes de informação. Seu caráter sistemático e abrangente admite com dificuldade a introdução de novos dados - pela ampliação do campo documental ou pela reinterpretação de fontes já conhecidas - a não ser na medida em que confirmem seus pressupostos ${ }^{19}$. Abrir as portas à balbúrdia da realidade dos documentos, explorar suas incongruências, fugir das analogias fáceis buscando sobretudo a diferença pode ser, às vezes, um meio para se revitalizar os próprios modelos, para descobrir ordenações diversas, relações insuspeitadas.

Nem se pode afirmar que a historiografia tenha permanecido insensível a isto: manifestase, nos últimos anos, uma tendência crescente para se privilegiarem perspectivas mais históricas, dando conta de processos a longo prazo, valorizando ritmos que podem ser lentos, contínuos e diferenciados regionalmente; buscando a gênese e os desenvolvimentos e não apenas avaliando os resultados (como fazem, via de regra, os modelos). 
A documentação arqueológica se adapta muito bem a essa busca de uma maior profundidade cronológica. Do ponto de vista da Arqueologia, em particular, é possível inserir o grande desenvolvimento produtivo do final da República e do Principado num longo processo de densificação da ocupação humana que remonta à época do Bronze e se intensifica a partir do século VIII a.C., como parte da progressiva integração da Península no circuito do intercâmbio de idéias e bens do Mediterrâneo, processo que parece ocorrer sem rupturas drásticas, embora com ciclos longos de crescimento e retração (Potter, 1985, p. 72 e ss.).

\section{Arqueologia rural e tradição textual}

Ao lado de uma documentação escrita relativamente numerosa, mesmo que de difícil interpretação, os dados arqueológicos, cuja quantidade cresce constantemente, têm fornecido algumas peças importantes para acompanharmos esse processo em seus momentos de expansão e inflexão. Os suportes de informação são de caráter variado e multiforme englobando, potencialmente, todo e qualquer vestígio da vida material romana, na medida em que se possa relacioná-lo com o mundo da produção, do consumo e da troca. Em vista da importância crucial da agricultura no conjunto da produção econômica no período romano, as fontes de informação de origem extra-urbana revestem-se de um grande interesse. Como mostram os levantamentos de superfície efetuados na Etrúria meridional, algumas regiões da Península conheceram um notável adensamento do habitat rural a partir, sobretudo, do terceiro século a.C. ${ }^{20}$.

Os sítios rurais, que conhecemos por escavações e prospecções, representam, em grandé parte, antigos núcleos de fazendas, sedes de unidades produtivas que foram, nos séculos finais da República, o grande motor da expansão agrícola na Itália. As ruínas desses edifícios rurais constituem uma categoria documental complexa, cujo estudo exige uma análise acurada de suas estruturas arquitetônicas, bem como de uma vasta gama de produtos artesanais, elaborados no local ou importados dos centros urbanos. A história de tais edifícios é portanto, e simultaneamente, um excelente índice dos processos econômicos em curso na Península e sua materialização mais concreta: um ponto focal para se entender esta questão central da História Antiga, a da relação entre campo e cidade, e para se assentar o debate sobre o desenvolvimento das atividades econômicas no mundo romano.

Esses edifícios rurais, que sediavam e organizavam a exploração dos territórios agrícolas, possuem, enquanto categoria documental, algumas características específicas, com as quais podemos delimitar sua importância como fonte de informação. A primeira delas é sua quase ubiquiidade: presentes em quase toda a Península, mesmo nas áreas mais internas (com exceção das regiões mais elevadas da cadeia apenínica), os edifícios rurais compõem uma categoria documental numericamente significativa e que, pela atividade arqueológica, cresce constantemente. Sua presença maciça no subsolo italiano denuncia uma densidade de ocupação extremamente elevada no período romano, insuperada, em muitas regiões, até meados de nosso século. Além disso, o interesse por tais sítios iniciou-se cedo na cultura ocidental: desde o Renascimento, ao menos, os restos de edifícios rurais têm sido objeto de descrições e escavações e o levantamento dos vestígios visíveis ou aflorantes possui já uma longa história. Existe, portanto, um notável corpus documental já constituído que pode e deve servir como ponto de partida para o estudo da organização do espaço rural e de suas formas arquitetônicas.

Mas não é só isso. Há um aspecto que acentua a especificidade dos edifícios rurais como documento material. Como se sabe, a tradição textual legou-nos raros elementos da cultura técnica romana e de sua literatura. Possuímos apenas uns poucos manuais de arquitetura e de engenharia militar, além da grande enciclopédia de Plínio, que em meados do século I de nossa era resumiu, na sua Historia Natural, saberes técnicos de diversas origens. $O$ interesse dos copistas 

algumas reflexões.

medievais, no entanto, garantiu a preservação de alguns manuais romanos - distribuídos entre meados do século II a.C. e o Principado - que descrevem, em detalke, os princípios fundamentais da agricultura romana em seu momento mais dinâmico ${ }^{21}$.

Através deles podemos vislumbrar como, para a aristocracia romana, deveria ser o funcionamento ideal de suas fazendas, ter uma noção de sua extensão e do tipo de mão de obra empregado, dos produtos elaborados e de sua destinação. Podemos, além disso, saber como representavam seus edifícios rurais para si mesmos, que funções estes deviam preencher, a que necessidades atendiam - não apenas econômicas, mas sociais no sentido mais amplo. Tais autores, o que para nós é de grande importância, revelaram um aguçado interesse pelas sedes de suas propriedades, ou uillae rusticae, da qual dão imagens detalhadas, mesmo que difíceis de interpretar. Nestes manuais, os edifícios rurais aparecem como algo mais que meros núcleos habitacionais: são unidades produtivas em si, congregando o instrumental rústico, as reservas de água, os depósitos e celeiros e, sobretudo, centralizando o beneficiamento da produção agrícola, com prensas e moinhos sofisticados. Essa preocupação com os edifícios reflete-se na busca de uma arquitetura ideal, na qual espaço e função encontrariam sua combinação mais útil, bela e produtiva ${ }^{22}$.

A essa literatura de caráter técnico somam-se diferentes registros escritos sobre os edifícios rurais, que demonstram uma intensa preocupação das elites romanas com as coisas do campo, fonte de suas rendas e local privilegiado para o exercício do otium. São cartas, poemas, escritos de caráter histórico ou moralizante. É preciso ressaltar a excepcionalidade desta documentação para o arqueólogo. As casas de fazenda romanas talvez sejam a única categoria arqueológica, o único elemento material do sistema produtivo romano, para o qual dispomos de um discurso escrito coerente e articulado, que evolui dentro de modos e tempos que podem ser determinados. A possibilidade de se confrontar estes textos com os restos arqueológicos é infinitamente maior do que para outros documentos materiais - na atribuição de funções a espaços e na interpretação do sentido cultural das formas e espaços arquitetônicos. Isto representa uma grande vantagem, mas traz também seus riscos.

O potencial informativo dos edifícios rurais, na verdade, é limitado por alguns fatores. Em primeiro lugar, o corpus documental, embora extenso, é representado em sua maioria por publicações de má qualidade, resultado freqüente de escavações apressadas ou mal conduzidas, que dificilmente respondem às questões mais prementes que tentamos colocar-lhes. Grande parte das descrições e dos levantamentos planimétricos de que dispomos é, na prática, inutilizável. Além disso, o corpus representa uma seleção operada ao longo de séculos (como veremos adiante), e que privilegiou determinados tipos de edifícios, em geral os mais evidentes e luxuosos, em detrimento daqueles mais simples que estão, certamente, sub-representados.

O defeito principal do corpus, contudo, não advém tanto de sua constituição, como do modo habitual de sua utilização. Persiste uma tendência em empregar os documentos arqueológicos como simples complemento às fontes escritas, como exemplificação ou ilustração destas ${ }^{23}$. Em muitos trabalhos, os escritores agrários aparecem como a chave, quase exclusiva, da interpretação dos edifícios escavados, em particular na atribuição de sentido e função a determinados aposentos ou lugares. Como se os textos escritos representassem uma descrição objetiva da realidade, imediatamente utilizável e absolutamente paralela aos restos arqueológicos! Como se todos os edifícios rurais romanos seguissem um mesmo receituário, obedecessem às mesmas regras, às mesmas prescrições de Catão, Varrão ou Columella!

Tal paralelismo é insustentável: documentos escritos e arqueológicos diferem radicalmente em suas condições de produção e seu emprego depende de procedimentos críticos totalmente diversos. No âmbito da tradição escrita, por exemplo, reconhece-se hoje que os textos dos escritores agrários não são relatos neutros, nem descrições "exatas", mas a expressão de determinados pontos de vista, de certas posturas, que dependem do lugar ocupado por seus autores na 
sociedade romana, de seus objetivos, do modo de sua inserção muna tradição "agronômica", do interesse de seu público e, até mesmo, de certas idiossincrasias.

A origem social de tais textos e, portanto, a representatividade de seu discurso, remete a segmentos sociais muito específicos, sobretudo aos senadores e cavaleiros residentes em Roma - e não, como se pressupõe muitas vezes, à totalidade do complexo mundo rural da Península. Os textos conservados, além disso, cobrem um arco cronológico de mais de três séculos, período que observou mudanças de grande porte na agricultura e na própria reflexão romana a respeito. Mas não é só isso: o ângulo descritivo dos escritores agrários varia enormemente, por vezes no interior de um mesmo texto. Certas referências são bastante específicas, remetendo a realidades regionais, locais ou mesmo, como em Catão, a unidades produtivas singulares e concretas; outras são excessivamente abstratas, representando generalizações sobre a agricultura itálica, ou mesmo mediterrânea, cujas condições de validade, para cada região, não podemos controlar. Em Columella, sobretudo, o discurso sobre a agricultura romana assume um caráter de "idealidade" e a descrição do real se confunde, freqüentemente, com seu projeto de uma fazenda perfeita, em que as condições de produção e os níveis de rentabilidade sejam ideais.

Como vemos, décadas de estudos detalhados deram à crítica da tradição textual certos parâmetros que, embora nem sempre observados, permitem circunscrever, com alguma precisão, os limites e o valor de suas informações. No campo da documentação arqueológica, contudo, a situação é bem menos alentadora. A função que lhe é atribuída nos estudos contemporâneos, de simples ilustração aos textos escritos, impediu, de certa forma, o desenvolvimento de uma crítica própria, autônoma, que pudesse explorar suas possibilidades informativas e fixar seus limites inerentes. Ao contrário da crença geral, os restos arqueológicos não são um dado bruto e direto sobre as realidades passadas, nem sua materialidade enquanto objetos thes confere uma segura "objetividade" informativa. De certo modo, sua interpretação é mais complexa, e determinada por mais recortes, do que aqueles próprios à informação escrita. Os vestígios arqueológicos representam, para cada período, uma parcela mínima do mundo material em que foram produzidos e utilizados, cuja extensão é delimitada por condições de deposição e de preservação que diferem de material a material e de sítio a sítio. Para um corpus documental como o nosso, que se constituiu através de séculos, temos ainda que considerar as diferentes condições de sua recuperação, os diversos métodos empregados, os interesses variados que informaram os levantamentos e escavações, o modo como pontos de vista concorrentes ou sucessivos influenciaram na interpretação dos edifícios e na produção de nossos documentos de base: relevos planimétricos, descrições de sítios e objetos, reprodução das relações estratigráficas e espaciais etc. Equacionar tais fatores, fixar certos parâmetros de crítica é, sem dúvida, o ponto de partida para se extrair dos dados arqueológicos informações mais seguras e independentes, diversas daquelas que obtemos dos textos escritos.

\section{Conclusão: Perspectivas}

Do que foi dito, podemos vislumbrar a existência de um espaço analítico pouco explorado, cuja contribuição para o estudo da agricultura e da economia romanas pode ser proveitosa. Para explorarmos este campo, contudo, devemos seguir certos passos, percorrer alguns caminhos que são quase obrigatórios. Não basta, como é corrente, pinçar sítios selecionados que ilustrem argumentos específicos ou confirmem eventuais hipóteses: é preciso, em primeiro lugar, efetuar um levantamento sistemático da documentação existente, constituindo um corpus abrangente e, ao mesmo tempo, coerente em termos espaciais e cronológicos. Para analisar este corpus é fundamental ter consciência das condições de produção de cada documento, desenvolvendo uma crítica apropriada ao material arqueológico. Os edifícios rurais são, também eles, artefatos, a 

algumas reflexões.

despeito de sua complexidade ou duração, e devem ser inseridos em seu contexto temporal e geográfico. Só assim poderemos compreender a origem das formas arquitetônicas do campo, sua difusão e evolução, suas determinações cronológicas, suas alterações de sentido e função. Enquadramento cronológico, tipologia, análise espacial, estudo das técnicas e materiais são instrumentos à disposição do arqueólogo que devem ser empregados como o fundamento de uma visão própria, que assuma o risco de partir do dado material para a totalidade social - uma visão para a qual o texto escrito seja indício, pista, auxílio, mas não a base única do processo de reconstrução da história passada.

Não é necessário, nem conveniente, acentuar em demasia os tons do contraste entre documento material e textual: ambos são produto de uma mesma época e, portanto, aspectos de um mesmo universo social, ainda que deste nos revelem facetas diferentes e que dependam de estratégias de pesquisa também diferenciadas. Seu uso combinado, embora difícil, é uma premissa básica para a escrita de uma história mais abrangente, mais "total". Mas isto nos obriga a empregar um outro tempo, uma perspectiva temporal adequada ao nosso objeto. A interpretação de períodos da História humana como sistemas mais ou menos fechados, auto-explicáveis, é útil para um tratamento comparativo entre momentos e espaços geográficos diferentes, mas prejudica a compreensão da História enquanto processo, enquanto permanente devir. Talvez seja o momento de renunciar momentaneamente aos modelos estanques, acompanhar passo a passo o lento evolver dos processos históricos, abandonando a busca das essências pelo estudo das gêneses, que tanto abominava ao pensamento "estruturalizante" dos anos 60/80. Os documentos arqueológicos têm, precisamente, essa capacidade precípua de abarcar e compreender as longas cadências, os processos lentos de mudança nas formas e funções que as sociedades atribuem ao mundo material. Mesmo no caso de uma documentação fragmentária, descontínua e com vícios de constituição, como aquela relativa aos edifícios rurais romanos, essa perspectiva é prometedora e merece ser experimentada.

\section{Notas}

1 - Assim Sombart definia sua "cidade-consumidora": "By a consumer city I mean one which pays for its maintenance not with its own products, because it does not need to. It derives its maintenance rather on the basis of a legal claims such as taxes or rents, without having to deliver return values", em Finley, 1984, p. 10. Para um uso indiscriminado do conceito veja-se Latouche,1970, p. 17 e ss.

2 - Não é nossa intenção criticar em detalhe os argumentos empregados em favor desse modelo. $\mathrm{O}$ uso que fazem das fontes romanas, contudo, parece sintomático. Citemos apenas um exemplo: no prefácio do De Agri cultura de Catão, de meados do II a.C., que Garnsey \& Saller tomam como expressão maior dessa "manifesta hostilidade", não se encontra qualquer crítica ou oposição ao comércio como tal, que é visto como mais lucrativo que a própria atividade agrícola. O que Catão acentuava, em seu texto, é que os rendimentos da agricultura eram mais estáveis e seguros, além de serem, politicamente, mais proveitosos. Mesmo o capítulo XLII do primeiro livro do De Officis de Cícero, peça obrigatória em raciocínios do gênero, distinguia muito claramente entre o pequeno comércio varejista, que considerava degradante, e o grande comércio (o comércio marítimo), ao qual Cícero não fazia nenhuma objeção. Sobre a participação dos próprios senadores no comércio, veja-se D'Arms,1980, p. $77-90$.

3 - Este último ponto parece ser uma variante do clássico argumento de Mickwitz em torno das deficiências dos cálculos contábeis entre os romanos (Mickwitz,1937). 
4 - Hopkins (1984, p. 20) segue uma linha análoga, ao afirmar que "quello di Roma e uno dei pochi esempi ben documentati di una società pre-industriale che subi un rapido cambiamento sociale in un periodo di stagnazione tecnica".

5 - Seu esforço conjunto resultou numa série de publicações coletivas, algumas bastante influentes, como Societa Romana e Produzione Schiavistica I-III (Bari, Laterza, 1981) e, sobretudo, Settefinestre - una villa schiavistica dell'Etruria romana (Modena, Panini, 1985). Ressalve-se que apresentamos aqui apenas linhas gerais, desconsiderando certas diferenças de postura entre os marxistas italianos e, mesmo, a própria evolução de seu pensamento.

6 - Mas dando uma grande importância, igualmente, ao desenvolvimento do artesanato urbano, cf. Pucci,1981, p. 99-121 e Carandini,1980, p. 17-18; 1981, p. 255-259.

7 - A periodização, como veremos, é bastante fluida, sobretudo para o período final desse processo - sua "crise".

8 - Numa área definida, aproximadamente, pelos rios Arno ao norte, Tibre a leste e pela península sorrentina ao sul, cf. Pucci,1985,I,1,17, que admite certas nuances.

9 - Observe-se que, para Rostovtzeff, o índice da crise era, sobretudo, a proliferação da produção de cerâmicas de luxo - a terra sigillatta - nas províncias ocidentais e que suas origens eram urbanas (Rostovtzeff, 1933, p. 236). Sem entrar no mérito da noção de crise como tal, vale lembrar que as fontes escritas prestam-se a diferentes interpretações, sobretudo o célebre Edito de Domiciano em 92 d.C. (Suetônio, Domit., VII,2), vejam-se, a respeito, Rostovtzeff,1933, p. 237-238, Purcel,1985, p. 1 e ss., Patterson,1987, p. 115 e ss. e, sobretudo, Tchernia, 1984, p. 483-484 e 1986, p. 221-230.

10 - Carandini aplica sua noção de bissetorialidade a uma passagem célebre de Columella (III,3), na qual o agrônomo romano defendia a rentabilidade de um vinhedo e que se constituiu numa das pedras de toque das discussões sobre a racionalidade econômica dos romanos. Sua interpretação da passagem é bastante original e interessante (para visões diferentes do mesmo trecho vejam-se Mickwitz,1937, p. 585-587, Martin,1971, p. 370-373, DuncanJones, 1982, p. 48-59, Finley,1980, p. 160)

11 - Uma crítica pertinente deste modelo encontra-se em Foxhall,1990, p. 99-100.

12 - Garnsey utiliza-se, para sua classificação, dos valores mínimos expressos nas tábuas alimentares de Veleia e dos Ligures Baebiani (66-75).

13 - Diversos autores têm insistido, recentemente, sobre a necessidade de se admitir uma maior complexidade na estrutura social do campo romano, vejam-se, em particular, as observações de Gabba,1982, p. 380-385, Vallat,1987, p. 329 e Foxhall,1990, p. 113.

14 - “A developing country” é como Duncan-Jones define o Império romano (Duncan-Jones,1978, p. 1).

15 - Garnsey/Saller,1987, p. 63; Carandini,1980, p. 12.

16 - "L'Anatomia della Scimmia" é, precisamente, o título de um livro de Carandini (1979).

17 - Veja-se, também, no mesmo volume, Schiavone,1978, p. 78-79.

18 - Vejam-se as observações de Finley, 1984, p. 5-6. Carandini, como vimos, supõe uma sucessão linear de três formas de apropriação do solo e de organização do trabalho na Itália romana: pequena propriedade camponesa, uilla escravista e latifúndio. Se lhe perguntassem a que modo de produção corresponderia o primeiro, diria sem dúvida, ao "modo de produção antigo" ou "arcaico", próprio das cidades-estados da Grécia arcaica e clássica e das romano-itálicas do período médio-republicano (Carandini,1980, LII; as uilla rusticae, como sabemos, ao "modo de produção escravista"; mas a que modo de produção corresponde o latifúndio? Que modelo seria aplicável a ele? 

algumas reflexões.

19 - Os arqueólogos marxistas italianos, por exemplo, projetam suas escavações (Settefinestre, Giardino Vecchio) como "testes" do modelo que empregam e que acaba sempre, reiteradamente, confirmado e fortalecido.

20 - Potter,1985:72, que fala numa verdadeira "explosão demográfica" na Etrúria meridional: o número de sítios atestados ao redor de Veios, por exemplo, cresceu de 16 a 137 entre os séculos VIII e VI a.C., atingindo 242 no final da República (Potter,1985, tabelas 2,3 e 5).

21 - São eles: o De Agri Cultura, de Catão, de meados do século II a.C.; o De Re Rustica, de Varrão, composto em forma dialógica no final da República; o De Re Rustica, de Columella, de meados do século seguinte, além dos livros XIV a XX da Enciclopédia de História Natural de Plínio, ligeiramente posteriores ao tratado de Columella. Uma obra mais tardia é o $D e R e$ Rustica de Paládio. Sobre os agrônomos romanos veja-se, com proveito, Martin, 1971.

22 - A associação entre beleza e rentabilidade é uma preocupação constante dos escritores agrários romanos, em particular de Varrão e Columella; veja-se a respeito Carandini,1985,I,1,117.

23 - Exemplo cabal desse tratamento ilustrativo da documentação arqueológica é a análise dos edifícios rurais por White, 1970 , p. 415-445

\section{Referências Bibliográficas}

BRUTTI, M. Introduzione, Analisi marxiste e societa antiche. Roma: Riuniti, 1978, p. 9-44.

CARANDINI, A. L'anatomia della scimmia. La formazione economica della societa prima del capitale. Turim: Boringhieri, 1979.

CARANDINI, A. Il vigneto e la villa dl fondo di Settefinestre nel Cosano: un casu di produzione agricola per il mercato transmarino, The Seaborne Commerce of Ancient Rome: Studies in Archaeology and History. Roma: American Academy, 1980, p. 1-10.

CARANDINI, A. Prefazione - "Quando la dimora dello strumento e l'uomo, Kolendo, J.L'Agricoltura nell'Italia Romana. Roma: Riuniti, 1980, IX-LX.

CARANDINI, A. Roma imperialistica: un caso di sviluppo precapitalistico, The Seaborne Commerce of Ancient Rome: Studies in Archaeology and History, Memoirs of the American Academy in Rome, vol: XXXVI, 1980, p. 11-20.

CARANDINI, A. Sviluppo e Crisi delle Manifature Rurali e Urbane, Societa Romana e Produzione Schiavistica II. Bari: Laterza, 1981, p. 249-260.

CARANDINI, A. Columella's vineyard and the rationality of the Roman economy. Opus, 2, 1, 1983, p. 177-203.

CARANDINI, A. et alii. Settefinestre. Una villa schiavistica nell'Etruria Romana. Modena: Panini, 1985.

D'ARMS, J. Republican Senators' involvement in commerce in the late Republic: some Ciceronian evidence, The Seaborne Commerce of Ancient Rome: Studies in Archaeology and History. Roma: American Academy, 1980, p. 77-90.

DUNCAN-JONES, R. The Roman Empire - Quantitative Studies (2nd ed.). Cambridge: University Press, 1982.

FINLEY, M. A Economia Antiga. Porto: Afrontamento, 1980.

FINLEY, M. The study of ancient Economy: further thoughts. Opus, 3, 1, 1984, p. 5-11.

FOXHALL, L. The dependant tenant: land leasing and labour in Italy and Greece, Journal of Roman Studies, LXXX, 1990, p. 97-114. 
GABBA, E. Per la storia della societa romana tardo-repubblicana. Opus, I, 2, 1982, p. 373-387.

GARNSEY, P. \& SALLER, R. The Roman Empire: economy, society and culture. Londres: Duckworth, 1987.

MARTIN, R. Recherches sur les agronomes latins et leurs conceptions economiques et sociales. Paris: Belles Lettres, 1971.

MICKWITZ, G. Economic Rationalism in Graeco-Roman Agriculture, The English historical Review, CCVIII, 1937, p. 577-589.

PATTERSON, J. Crisis: What crisis? Rural change and urban development in imperial appennine Italy, Papers of the British School at Rome, LV, 1987, p. 115-146.

POTTER, T. Storia del Paesaggio dell'Etruria meridionale. Archeologia e trasformazioni del territorio. Roma: NIS, 1985.

PUCCI, G. La Ceramica Italica (terra sigillata), Societa Romana e Produzione Schiavistica II. Bari: Laterza, 1981, p. 99-121.

PUCCI, G. Schiavitu romana nelle campagne. Il sistema della villa nell'Italia centrale. Settefinestre - una villa schiavistica nell'Etruria Romana. Modena: Panini, I, 1, 1985, p. 15-21.

PURCELL, N. Wine and Wealth in Ancient Italy. Journal of Roman Studies, LXXV, 1985, p. 1-19.

ROSTOVTZEFF, M. Storia Sociale ed Economica dell'Impero Romano. Florença: Nuova Italia, 1933.

SCHIAVONE, A. Per una rilettura delle "Formen": teoria della storia, dominio del valore d'uso e funzione dell'ideologia. Analisi marxiste e societa antiche. Roma: Riuniti, 1976, p. 75-106.

TCHERNIA, A. I vigneti italiani da Augusto a Domiziano: continuita e cambiamenti.Opus, III, 2, 1984, p. 477-486.

TCHERNIA, A. Le vin de l'Italie romaine. essai d'histoire economique d'apres les amphores. Roma: EFR, 1986.

VALLAT, J.P. Le paysage agraire du piedmont du Masique. Structures Agraires en Italie centromeridionale. cadastres et paysage ruraux. Roma: EFR, 1987, p. 315-378.

WHITE, K. Roman Farming. Ithaca: Conrell University Press, 1970.

GUARINELLO, Norberto L.L'Économie anciénne et l'archèologie rurale - quelques réflections. Classica, São Paulo, 7/8: 271-283, 1994/19995.

RESUMÉ: La documentation archéologique sur les édifices ruraux romains est aujourd'hui très abondante. Cependant, son intreprétation dépend directement des modèles disponibles pour expliquer le fonctionement de l'économie romaine. Cet article passe en revue deux de ces modèles et essaye de réflechir sur le rapport entre réalité empirique et modèles interprétatifs.

MOTS-CLÉS: Histoire Romaine, Archéologie Classique, Économie Ancienne, Archéologie du Paysage. 